\title{
Empyema Thoracis: A Clinical Study of 15 Cases in Tertiary Care Center
}

\author{
Authors
}

\section{Dr Rakesh Digambar Waghmare, Dr Rakhi Ashok Gosavi}

Department of Pulmonary Medicine, B.J.G.M.C \& Sassoon General Hospital, Pune Jayprakash Narayan Road, Near Pune Railway Station,, Pune-1

Correspondence Author

Dr. Rakhi Ashok Gosavi

B.J. Medical College, Ladies Hostel, "F” Block, Behind Sent Helena's School, Charch Road, Pune - 411001 Phone No 9881825252, Email: dr.rakhigosavi@ gmail.com

\begin{abstract}
Background: Empyema thoracis, defined as a collection of pus in the pleural space

Aims: To study the clinical, microbiological and treatment outcomes obtained by ICD care in tertiary care hospital.

Methodology: A prospective study conducted in tertiary care hospital in 15 patients diagnosed as empyema thoracis

Results: In the study, male-to-female ratio was 2:1. Their mean age was 47.86 years. The commonest symptoms at presentation were cough, seen in 14 patients (93.33\%).Sputum was positive for AFB by ZN stain in 6 patients $(40 \%)$ out of 15 in present study. Pseudomonas were isolated most frequently from empyema fluid in 6 patients (40\%), followed by sterile pus in 4 (26.66\%). Patient was treated with tube thoracostomy connected to an underwater seal drainage and systemic antibiotics, with this approach complete expansion of the lung seen in 8 patients $(53.33 \%)$, while 3 patients $(20 \%)$ had only partial expansion, 2 (13.33\%) patients had empyema with bronchopleural fistula (BPF) and referred to the cardiovascular thoracic surgery department for decortication.

Conclusion: It can be concluded from the above study that, all patients of empyema have chronic morbidity and Intercostal drainage with under water seal was the treatment of choice with most acceptable outcome. If the procedure is performed with appropriate care and adequate post ICD care is provided then chances of developing complications are minimal and most of them are easily curable.

Keywords: Intercostal drainage tube, Empyema with bronchopleural fistula (BPF).
\end{abstract}

\section{Introduction}

An empyema is, by definition, pus in the pleural cavity. The diagnosis and treatment of empyema by surgical drainage was first described by Hippocrates in around 600 B.C. ${ }^{[1]}$ The first documented description of a closed tube drainage system for the drainage of empyema was by
Hewett in $1867^{[2]}$. Empyema is an illness with significant morbidity ${ }^{[3,4]}$ and mortality ${ }^{[5,6]}$. But acute or chronic infection of pleura is very common in developing countries probably due to poor nutrition and improper management. In India, empyma with pre- existing disease is treated with antimicrobial multiple antitubercu- 
lous drugs and Intercostal drainage tube or surgery $^{[7]}$. This results in long hospital stay. Many with poor status cannot be subjected to surgery, so Intercostal drainage tube with antimicrobial agents is alternatively practised.

The present study is aimed at studying the etiology, bacteriological features, the clinical presentation, diagnostic modalities, the different modalities of treatment available for this condition and the overall treatment outcome in a teaching hospital.

\section{Material and Methods}

This is a study conducted in tertiary care hospital, which include 15 indoor patients with empyema. Valid informed consent and detailed history were taken of all the patients. All routine investigations were done. Pus examination for culture and sensitivity and sputum for AFB microscopy were done in all cases to identify probable etiology. The outcome of the patients in response to various modes of treatment were noted.

\section{Results}

A total of 15 patients were included in study. Data was meticulously collected and entered in the MS EXCEL spreadsheet and analyzed. On analysis of the data following observations and results were found in the present study.

In the present study out of 15 patients, total male 10(66.66\%), female $5(33.33 \%)$ [Table 1]. Thus the male-to-female ratio was $2: 1$. Their mean age was 47.86 years. The commonest symptoms at presentation were cough, seen in 14 patients (93.33\%); dyspnea in 12 patients $(80 \%)$; followed by chest pain in 10 patients $(66.66 \%)$ and fever in 8 patients $(53.33 \%)$ [Table 2 ].

In the present study 8 patients $(53.33 \%)$ had Past history of tuberculosis, 9 patients were $(60 \%)$ smokers and 9 (60\%) were alcoholic [Table 3,4]. Sputum was positive for AFB by ZN stain in 6 patients $(40 \%)$ out of 15 in present study [Table $5]$.

In the present study, Pseudomonas were isolated most frequently from empyema fluid in 6 patients
(40\%), followed by sterile pus in 4 (26.66\%), Klebsiella in $3(20 \%)$ patients and Staphylococcus Aureus in 2 (13.33\%) [Table 6].

Patient was treated with tube thoracostomy connected to an underwater seal drainage and systemic antibiotics, with this approach complete expansion of the lung seen in 8 patients $(53.33 \%)$, while 3 patients $(20 \%)$ had only partial expansion, $2(13.33 \%)$ patients had empyema with bronchopleural fistula (BPF) and referred to the cardiovascular thoracic surgery department for decortication, 1 patient left against medical advice and 1 patient expired due to acute respiratory failure [Table 7]

1) Sex Incidence

\begin{tabular}{|l|c|c|}
\hline Sex & No. of patients & $\%$ \\
\hline Male & 10 & 66.66 \\
\hline Female & 5 & 33.33 \\
\hline Total & 15 & 100 \\
\hline
\end{tabular}

2) Clinical presentation of empyma

\begin{tabular}{|l|c|c|}
\hline Symptoms & No. of patients & $\%$ \\
\hline Dyspnoea & 12 & 80 \\
\hline Cough & 14 & 93.33 \\
\hline Chest Pain & 10 & 66.66 \\
\hline Fever & 8 & 53.33 \\
\hline
\end{tabular}

\section{3) Relation with smoking}

\begin{tabular}{|l|c|c|}
\hline Smoking & No. of patients & $\%$ \\
\hline Smokers & 9 & 60 \\
\hline Non Smokers & 6 & 40 \\
\hline Total & 15 & 100 \\
\hline
\end{tabular}

\section{4) Relation with Alcohol}

\begin{tabular}{|l|c|c|}
\hline Alcoholic & No. of patients & $\%$ \\
\hline Alcoholic & 9 & 60 \\
\hline Non Alcoholic & 6 & 40 \\
\hline Total & 15 & 100 \\
\hline
\end{tabular}

\section{5) Sputum for Acid Fast Bacilli}

\begin{tabular}{|l|c|c|}
\hline Acid Fast Bacilli & No. of patients & $\%$ \\
\hline Positive & 6 & 40 \\
\hline Negative & 9 & 60 \\
\hline Total & 15 & 100 \\
\hline
\end{tabular}




\section{6) Bacteriology}

\begin{tabular}{|l|c|c|}
\hline Organism & No. of patients & $\%$ \\
\hline No Organism & 4 & 26.66 \\
\hline Pseudomonas & 6 & 40 \\
\hline Klebsiella & 3 & 20 \\
\hline Staphylococcus Aureus & 2 & 13.33 \\
\hline Total & 15 & 100 \\
\hline
\end{tabular}

\section{7) Outcome of Patients}

\begin{tabular}{|l|c|c|}
\hline Outcome & No. of patients & $\%$ \\
\hline Complete Expansion & 8 & 53.33 \\
\hline Partial Expansion & 3 & 20 \\
\hline Left against medical advice & 1 & 6.66 \\
\hline Transferred for Thoracic Surgery & 2 & 13.33 \\
\hline Death & 1 & 6.66 \\
\hline Total & 15 & 100 \\
\hline
\end{tabular}

\section{Discussion}

The mean age of presentation is 47.86 yrs which is consistent with 2 studies A S Geha ${ }^{[8]}$, in M M Sherman $^{[9]}$ which show highest incidence of empyema after 40 yrs of age group.

In present study, male outnumbered female in the ratio of 2:1. The percentage of male incidence of disease in different studies is as follows: R.K. Tandon et al, 75\% ${ }^{[10]}$, A.S. Geha et al ${ }^{[8]} 75.6 \%$, Kamat et al ${ }^{[11]} 88 \%$, Emerson et al ${ }^{[12]} 83.4 \%$. In present study it was $66.66 \%$. It is obvious that males are more prone to mechanical stresses due to strenuous work, smoking and tall stature, tuberculosis, chronic bronchitis with emphysema all these being more common in males ${ }^{[13]}$.

The study done by Kamat et al ${ }^{[11]}$ reported cough (94\%) to be the most common symptom. This was followed by fever (76\%), chest pain $(75 \%)$ and dyspnea (53\%). The prevalence of cough $(93.33 \%)$ matches that of the study conducted by Kamat et $\mathrm{al}^{[11]}$, whereas dyspnea $(80 \%)$ encountered more frequent \& chest pain $(66.66 \%) \&$ fever $(53.33 \%)$ encountered less frequently in our patients.

In Kamat et $\mathrm{al}^{[11]}, 52 \%$ are smokers, while in present study $60 \%$ patients are smoker.

In our series, we reported positive culture report of pus in $73.33 \%$ of cases, Gupta A et al ${ }^{[14]}$ reported 54\% positive culture fluid while Bryant et $\mathrm{al}^{[15]}$, Sherman et $\mathrm{al}^{[9]}$ and Emerson et $\mathrm{al}^{[12]}$ reported $67.8 \%, 66 \%$ \& $69.6 \%$ respectively. In present series fluid culture sensitivity report was negative in $26.66 \%$.

In Kamat et $\mathrm{al}^{[11]}$ and Gupta $\mathrm{A}$ et $\mathrm{al}^{[14]}, 57 \%$ and $34 \%$ cases were positive for sputum acid-fast bacilli respectively, whereas in our study it was 40 $\%$.

Most common organism isolated from pus was Pseudomonas (40\%) followed by Klebsiella (20\%) and Staphylococcus aureus (13.33\%) whereas in study conducted by Gupta A et al ${ }^{[14]}$ most common organism isolated was Pseudomonas $(22 \%)$ followed by Staphylococcus aureus (16\%) followed by E. Coli (12\%).

In present study, Intercostal drainage tube insertion was done in all the patients and it gives good results. Complete and partial expansion was seen in $53.33 \%$ and $20 \%$ of patients respectively. In BK Khanna et $\mathrm{al}^{[16]}, 63 \%$ of patients and Gupta $A$ et $\mathrm{al}^{[14]} 50 \%$ of patients show complete expansion of lung. 2 patients were sending for Decortication. So, we suggested that closed Intercostal drainage must be done immediately after hospitalization and pus collected should be monitored every day. Appropriate antibiotics therapy should be started. The overall recovery rate in this series with ICD treatment was $53.33 \%$.

\section{Conclusion}

It can be concluded from the above study that, all patients of empyema have chronic morbidity and Intercostal drainage with under water seal was the treatment of choice with most acceptable outcome. If the procedure is performed with appropriate care and adequate post ICD care is provided then chances of developing complications are minimal and most of them are easily curable.

\section{References}

1. Adams F. The genuine works of Hippocrates, Baltimore: William and Wilkins Company; 1939;51 - 2 . 
2. F. C. Hewett, "Thoracentesis: the plan of continuous aspiration," The British Medical Journal, vol. 1, no. 793, p. 317, 1876.

3. Jess P, Brynitz S, Friis Møller A. Mortality in thoracic empyema. Scand J Thorac Cardiovasc Surg 1984;18:85-7.

4. Hutter JA, Harari D, Braimbridge MV. The management of empyema thoracis by thoracoscopy and irrigation. Ann Thorac Surg 1985;39:517-20.

5. Varkey B, Rose HD, Kutty CP, Politis J. Empyema thoracis during a ten- year period. Analysis of 72 cases and comparison to a previous study (1952 to 1967). Arch Intern Med 1981;141:1771-6.

6. Lemmer $\mathrm{JH}$, Botham MJ, Orringer MB. Modern management of adult thoracic empyema. J Thorac Cardiovasc Surg 1985;90:849-55.

7. Storm HK, Krasnik M, Bang K, FrimodtMøller N. Treatment of pleural empyema secondary to pneumonia: thoracocentesis regimen versus tube drainage. Thorax 1992;47:821-824.

8. Geha AS. Pleural empyema. Changing etiologic, bacteriologic, and therapeutic aspects. J Thorac Cardiovasc Surg. 1971; 61:626-35.

9. Sherman MM, Subramanian V, Berger RL. Managment of thoracic empyema. Am J Surg. 1977; 133:474-9.

10. Tandon RK, Misra OP. Clinicopathological study of thoracis empyema and evaluation of its surgical treatment. Indian J Chest Dis. 1974;16:21-30.

11. Kamat SR, Kadalkar SS, Maydeo DV, Walimbe S, Kulkarni KG, Hanmantgad $\mathrm{RR}$, et al. Aprospective study of one hundred cases of chronic empyema in Bombay. Lung India 1985;3:15-9.

12. Emerson JD, Boruchow IB, Daicoff GR, Bartley TD, Wheat MW Jr. Empyema. J Thorac Cardiovasc Surg. 1971;62:967-72.
13. Bhatnagar R, Maskell NA. Treatment of complicated pleural effusions in 2013. Clin Chest Med. 2013;34:47-62.

14. Gupta A, Dutt N , Patel N.The different treatment modalities of pyopneumothorax - A study of 50 cases. International journal of Medical Science and Public Health,2013, vol 2,issue 3,609-12.

15. Bryant LR, Chicklo JM, Crutcher R, Danielson GK, Malette WG, Trinkle JK. Management of thoracic empyema. J Thorac Cardiovasc Surg. 1968;55:850- 8.

16. Tandon RN, Khanna BK. Management of Tuberculous Empyema. Indian J Tuberc. 959;7:95-99. 